\title{
Wanted dead or alive: characterizing likelihood of juvenile Steller sea lion predation from diving and space use patterns
}

\author{
Amanda M. Bishop ${ }^{1, *}$, Alexandra K. Dubel ${ }^{2}$, Renae Sattler ${ }^{3}$, Casey L. Brown ${ }^{4}$, \\ Markus Horning ${ }^{1}$
}

\author{
${ }^{1}$ Alaska SeaLife Center, Seward, AK 99664, USA \\ ${ }^{2}$ Florida State University, Tallahassee, FL 32306, USA \\ ${ }^{3}$ Alaska Department of Fish and Game, Palmer, AK 99645, USA \\ ${ }^{4}$ Oregon Department of Fish and Wildlife, La Grande, OR 97850, USA
}

\begin{abstract}
Understanding linkages between behaviors and mortality risk is critical for managing populations. Juveniles constitute a particularly vulnerable life stage, with growing evidence that within stages, individual strategies may be associated with greater predation risk and mortality. These forms of predator-prey dynamics are rarely explored in marine environments due to difficulties in confirming vital status of individuals, and the lack of data sets that link mortality to behavior. We analyzed 2 concurrently collected data sets for juvenile Steller sea lions Eumetopias jubatus in the Gulf of Alaska to examine associations between mortality and specific behavioral patterns. Forty-five juvenile Steller sea lions were instrumented with external satellite tags and internally implanted vital rate transmitters (LHX tags). From 2005 through 2018, 25 juveniles remained alive and 20 died (18 confirmed predation). Using a binomial generalized linear mixedeffects model, we tested whether the probability of individual mortality was associated with seasonally specific dive patterns (time wet, dive depth) or horizontal movement patterns (home range size, average trip distance). Additionally, in 3 cases, external tags were transmitting until death. To examine links between fine-scale ante-mortem behavioral patterns and predation susceptibility, we compared dive patterns recorded during the last $3 \mathrm{~d}$ of data transmissions (both for animals which survived and for those which died) to dive patterns recorded during other periods at sea. Results suggest individuals that spent more time dry or dove shallower had a greater mortality probability, which could reflect foraging tactics of predators. This study highlights the effectiveness of combining multiple telemetry systems for exploring the vulnerability of individuals to the consumptive effects of predators.
\end{abstract}

KEY WORDS: Predation · Bio-logging $\cdot$ Diving behavior $\cdot$ Eumetopias jubatus $\cdot$ Risk $\cdot$ Marine mammal

\section{INTRODUCTION}

Predator-prey dynamics include a suite of ecological interactions that, along with resource distribution, underpin animal movements and space use (Lima \& Dill 1990). These dynamics manifest through non-consumptive or consumptive effects

\footnotetext{
${ }^{*}$ Corresponding author: amybi@alaskasealife.org
}

of predators. Non-consumptive effects are changes in the behaviors of individual prey as a result of perceived risk or 'fear', and can include increased vigilance (Laundré et al. 2001, Ciuti et al. 2012), decreased time spent foraging (Hamilton \& Heithaus 2001, Ciuti et al. 2012), foraging in sub-optimal habitats (Wirsing et al. 2008), and/or broad

(C) The authors 2019. Open Access under Creative Commons by Attribution Licence. Use, distribution and reproduction are unrestricted. Authors and original publication must be credited. 
changes in space use (Tolon et al. 2009, Breed et al. 2017, Kohl et al. 2018). Alternatively, the consequence of consumptive effects is the mortality of an individual.

Both forms of predator effects have associated fitness consequences. Fear or risk-induced changes to behavior and space use may impact fitness, but there is debate as to the extent to which these effects scale to populations or ecosystems (Kauffman et al. 2010). Alternatively, predation mortality can directly shape populations and ecosystems through trophic cascades, altered sex ratios, or predator-induced selective pressures (Réale \& Festa-Bianchet 2003, Ripple et al. 2016). Therefore, susceptibility to predation has significant management implications for endangered species (Blumstein et al. 2001, Iribarren \& Kotler 2012), especially for populations that have limited ability to absorb mortalities due to low numbers and/or low reproductive rates, or if predation on juveniles constrains recruitment.

Increased susceptibility to predation is well established for certain life-history stages, conditions, and habitats. Old and juvenile animals are typically at a greater risk of predation relative to other life-history stages (Byström et al. 1998, Lundvall et al. 1999, Réale \& Festa-Bianchet 2003, Frid et al. 2009, Walsh \& Reznick 2009, Choh et al. 2012). The use of habitat with a greater probability of encountering predators can also increase the risk of predation (Lone et al. 2014). However, it is becoming increasingly apparent that behavioral traits can also be associated with individuals' susceptibility to predation (Jones \& Godin 2010, Krams et al. 2013). For example, in years with high predation rates, there was moderate selection for survival of female bighorn sheep Ovis canadensis with bold behavioral types and increased predation of docile animals (Réale \& Festa-Bianchet 2003).

The links between individuals' behaviors and mortality have been explored in laboratory and terrestrial settings (Jones \& Godin 2010, Réale \& FestaBianchet 2003), but there is a considerable lack of empirical studies in marine ecosystems (Hays et al. 2016). While the fate of individuals in marine environments is commonly tracked via mark-recapture efforts (Shuert et al. 2015), observations of predation events have been labeled as 'empirically intractable' (Williams et al. 2004) for marine vertebrates. Due to this absence of observed mortalities, most of our understanding of the predator-prey dynamics in marine ecosystems focuses on non-consumptive effects through theoretical models of resource and risk trade-offs (Frid et al. 2006, 2007, 2009, Wirsing et al. 2008) and behavioral assessments of how risk shapes animals' movements and space use (Hammerschlag et al. 2015, Breed et al. 2017). Here, we explore how advances in biotelemetry provide a novel opportunity to investigate the susceptibility to predation in situ for a marine meso-predator by combining observations of mortality and individual behaviors.

After an $80 \%$ population decline, Steller sea lions Eumetopias jubatus were listed as endangered in 1997 throughout the western extent of their distribution (western distinct population segment [wDPS], west of $\left.144^{\circ} \mathrm{W}\right)$ (62 Federal Register 24345). At the height of the decline, juvenile survival appeared to be depressed (Pascual \& Adkison 1994, York 1994, Holmes \& York 2003). Presently, some regions of the wDPS such as the Gulf of Alaska are stable or slightly increasing (NMFS 2010), but data from telemetry studies show that in these regions, $91.7 \%$ of juvenile mortalities $(95 \%$ CI: $78-100 \%$ ) can be attributed to predation (Horning \& Mellish 2009, 2012). Contemporary levels of predation pressure have thus been suggested as one potential driver behind the lack of the recovery of the wDPS as a whole. Since 2003, new biotelemetry methods have been developed and applied to explore survival of and predation on juvenile Steller sea lions in the Gulf of Alaska (Horning \& Hill 2005, Mellish et al. 2007, Horning et al. 2008, Horning \& Mellish 2009). The implantable Life History Transmitter (LHX tag) records sensor data over the course of an animal's life (Horning \& Hill 2005). Following the death of an animal, the positively buoyant LHX tags emerge from the dismembered, digested, or decomposing carcass and begin transmitting data to ARGOS satellites, including temperature profiles and the date and time of death (Horning \& Mellish 2009, 2014). Post hoc, the temperature data can be used to characterize whether the mortality event was due to predation or other natural causes, with some additional differentiation of the type of possible predator (Horning \& Mellish 2009, 2014).

By pairing 'observations' of predation from LHX tags with data from traditional, externally attached telemetry devices for tracking animal movement and behavior, this bio-logging system provides a unique opportunity to gain a better understanding of the vulnerability of juveniles in an endangered marine species to the consumptive effects of predators. The objective for this study was to assess whether individual juvenile Steller sea lions' behavioral patterns (horizontal/vertical movements) are associated with 
greater probability of predation at coarse and fine temporal scales.

\section{MATERIALS AND METHODS}

\subsection{Study area and animals}

Juvenile Steller sea lions, between 12 and 26 mo of age (age determined as per Raum-Suryan et al. 2004, King et al. 2007), were captured from the Prince William Sound $\left(60.77^{\circ} \mathrm{N}, 147.61^{\circ} \mathrm{W}\right)$ and Kenai Fjords region of the Gulf of Alaska $\left(59.87^{\circ} \mathrm{N}, 149.31^{\circ} \mathrm{W}\right)$, as described in Mellish et al. (2006, 2007), Thomton et al. (2008) and Bishop et al. (2018). Briefly, between 2005 and 2014, 45 animals (17 females, 28 males) were captured in the field and transported to the Alaska SeaLife Center for a period of temporary captivity lasting up to 3 mo (Table 1). During this time, animals were monitored through a range of health assessments; additional details on holding, husbandry and transport can be found in Mellish et al. $(2006,2007)$.

\subsection{Instrumentation}

During temporary captivity, animals underwent surgery for the implantation of $1(n=2)$ or $2(n=43)$ life-history tags (LHX1 and LHX2 tags, Wildlife Computers) into the peritoneal cavity using a standard aseptic technique and anesthesia (Horning et al. 2008). All animals underwent postoperative monitoring for a minimum of $1 \mathrm{wk}$ (up to $6 \mathrm{wk}$ ) (Mellish et al. 2007), after which they were released at Lowell Point, Alaska (60.08 N, 149.43 W). Prior to release, 44 animals were instrumented with external satellite data recorders (SDRs: either SDR-T16, SPOT 5, or SPLASH, Wildlife Computers) mounted to their dorsal pelage as described in Mellish et al. (2007) and Thomton et al. (2008). SDRs were programmed with continuous duty cycles and recorded dive data (dive depth, dive duration, and time at depth) in 4 and $6 \mathrm{~h}$ histogram bins (Thomton et al. 2008). Dive data were redundantly transmitted through the Argos satellite system, but reception is subject to satellite coverage. Most dive data were received when animals were hauled out. Location estimates were provided by the Argos service provider (Woods Hole Group), and are based on the Doppler shift detected in multiple sequential transmissions being received during 1 pass of low polar orbiting satellites. Data and location estimates were obtained until the SDRs were shed, or until the tag's batteries were exhausted and the tags no longer transmitted. The average SDR transmission duration was $77.23 \mathrm{~d}$ (Bishop et al. 2018). Control studies found no evidence of an effect of temporary captivity, surgery, or telemetry implants on the postrelease diving, horizontal movements, or survival of animals in this study (Mellish et al. 2007, Thomton et al. 2008, Shuert et al. 2015, Bishop et al. 2018).

\subsection{Horizontal movement behaviors}

This study applied the utilization distributions (UDs) previously derived for each animal in Bishop et al. (2018). In brief, filtered locations were interpolated using a continuous time-correlated random walk state-space model (crawl package in R). From the resulting pseudolocations, seasonal kernel density grids were generated using fixed likelihood cross-validation bandwidth (Geospatial Modeling Environment, GME v0.7.2.0). Seasons were defined as spring-summer (March-August) and fall-winter (September-February). Isopleths were calculated in GME, and the $95 \%$ UD area $\left(\mathrm{km}^{2}\right)$ was defined as the seasonal home range for each individual. Two animals did not meet the minimum sample size requirement for kernel density analysis (Seaman et al. 1999), resulting in a final data set of 50 UDs across 42 animals (some individuals may have a UD in more than one seasonal period; Table S1 in the Supplement at www.int-res.com/articles/suppl/n040p357_supp.pdf).

The average horizontal distance traveled per foraging trip, defined as the locations at sea between 2 subsequent haul-out events, was calculated for each animal seasonally. To identify trips within an animal's track, each pseudolocation derived from the state-space model was classified as 'wet' or 'dry' based on dive histogram data for that date and time. For SDR-T16 and SPOT 5 tags, the wet/dry status was recorded every $20 \mathrm{~min}$. For SPLASH tags, timeline data reported percentage of time dry per hour, and hours where $>50 \%$ of the time was dry were considered hauled out (Thomton et al. 2008). All wet locations between known dry states were considered a single trip, and were given a unique trip ID. Overall, the location and dive data sets lined up $75.6 \%$ of the time. In cases where a series of pseudolocations were wet, but were followed by positional data with no corresponding wet/dry information, the trip or haul-out ID was reset to indicate a new trip, providing a conservative estimate of trip distance in these cases. Distance traveled (m) for each trip was calculated as the Euclidean distance of the entire path in ArcGIS 10.6 (Table S1). 
Table 1. Descriptions of tagged animals in the study: sex, age at release, release date, season(s) (SS: spring-summer; FW: fall-winter) for which there are tracking and diving data available, and vital status (alive/dead). For animals that died, information on the season in which the animal died, date of mortality event, and cause of death (Horning \& Mellish 2009, 2014) are provided. Whether the horizontal and vertical data from each individual were included in the 2 binomial models is indicated. A mortality date followed by ${ }^{+}$indicates the individual died while wearing its external tag

\begin{tabular}{|c|c|c|c|c|c|c|c|c|c|c|}
\hline ID & Sex & $\begin{array}{l}\text { Age at } \\
\text { release } \\
(\mathrm{mo})\end{array}$ & $\begin{array}{c}\text { Release } \\
\text { date } \\
\text { (mm/dd/yy) }\end{array}$ & $\begin{array}{l}\text { Tracking } \\
\text { data } \\
\text { season(s) }\end{array}$ & $\begin{array}{l}\text { Vital } \\
\text { status }\end{array}$ & $\begin{array}{c}\text { Season } \\
\text { died }\end{array}$ & $\begin{array}{c}\text { Mortality } \\
\text { date } \\
\text { (mm/dd/yy) }\end{array}$ & $\begin{array}{l}\text { Cause } \\
\text { of death }\end{array}$ & $\begin{array}{c}\text { Horizontal } \\
\text { binomial } \\
\text { model }\end{array}$ & $\begin{array}{c}\text { Vertical } \\
\text { binomial } \\
\text { model }\end{array}$ \\
\hline LHX2_07 & $\mathrm{F}$ & 22 & $5 / 14 / 14$ & SS & Dead & SS & $6 / 28 / 15$ & Predation & $\mathrm{Y}$ & $\mathrm{N}$ \\
\hline LHX2_08 & $\mathrm{F}$ & 12 & $5 / 14 / 14$ & SS & Dead & SS & $4 / 19 / 15$ & Predation & $\mathrm{Y}$ & $\mathrm{N}$ \\
\hline LHX2_11 & $\mathrm{F}$ & 26 & $8 / 28 / 14$ & FW & Dead & FW & $1 / 25 / 16$ & Predation & $\mathrm{Y}$ & $\mathrm{N}$ \\
\hline TJ27 & M & 22 & 4/16/06 & SS & Dead & SS & $3 / 19 / 07$ & Inconclusive & $\mathrm{Y}$ & $\mathrm{N}$ \\
\hline TJ32 & M & 15 & $10 / 10 / 07$ & FW & Dead & FW & $2 / 25 / 08$ & Predation & $\mathrm{Y}$ & $\mathrm{Y}$ \\
\hline TJ33 & M & 15 & $10 / 10 / 07$ & FW & Dead & FW & $2 / 11 / 08^{+}$ & Predation & $\mathrm{Y}$ & $\mathrm{Y}$ \\
\hline TJ35 & M & 15 & 10/9/07 & FW & Dead & SS & 5/18/08 & Predation & $\mathrm{N}$ & $\mathrm{N}$ \\
\hline TJ43 & $\mathrm{F}$ & 16 & $11 / 12 / 08$ & FW, SS & Dead & FW & $2 / 4 / 12$ & Inconclusive & $\mathrm{Y}$ & $\mathrm{Y}$ \\
\hline TJ44 & M & 16 & $11 / 11 / 08$ & FW & Dead & FW & 11/7/09 & Predation & $\mathrm{Y}$ & $\mathrm{Y}$ \\
\hline TJ46 & M & 16 & $11 / 11 / 08$ & FW & Dead & FW & 1/6/10 & Predation & $\mathrm{Y}$ & $\mathrm{Y}$ \\
\hline TJ47 & $\mathrm{F}$ & 16 & $11 / 11 / 08$ & $\mathrm{FW}$ & Dead & $\mathrm{FW}$ & $1 / 17 / 09^{+}$ & Predation & $\mathrm{Y}$ & $\mathrm{Y}$ \\
\hline TJ51 & $\mathrm{F}$ & 13 & 7/21/09 & SS & Dead & FW & 10/21/09 & Predation & $\mathrm{N}$ & $\mathrm{N}$ \\
\hline TJ52 & M & 25 & 7/29/09 & $\mathrm{SS}, \mathrm{FW}$ & Dead & SS & 8/6/11 & Predation & $\mathrm{Y}$ & $\mathrm{Y}$ \\
\hline TJ54 & M & 13 & 7/21/09 & SS & Dead & SS & $5 / 12 / 10$ & Predation & $\mathrm{Y}$ & $\mathrm{Y}$ \\
\hline TJ57 & M & 17 & $11 / 24 / 10$ & FW, SS & Dead & FW & $9 / 27 / 11$ & Predation & $\mathrm{Y}$ & $\mathrm{Y}$ \\
\hline TJ58 & M & 17 & $11 / 23 / 10$ & FW & Dead & FW & $2 / 12 / 11^{+}$ & Predation & $\mathrm{Y}$ & $\mathrm{Y}$ \\
\hline TJ59 & M & 17 & $11 / 23 / 10$ & FW, SS & Dead & FW & 1/29/12 & Predation & $\mathrm{Y}$ & $\mathrm{Y}$ \\
\hline TJ62 & $\mathrm{F}$ & 12 & $6 / 29 / 11$ & SS & Dead & SS & $3 / 14 / 13$ & Predation & $\mathrm{Y}$ & $\mathrm{Y}$ \\
\hline TJ63 & M & 12 & $6 / 22 / 11$ & SS & Dead & FW & $12 / 2 / 11$ & Predation & $\mathrm{N}$ & $\mathrm{N}$ \\
\hline TJ64 & $\mathrm{F}$ & 12 & $6 / 22 / 11$ & SS & Dead & FW & $12 / 4 / 11$ & Predation & $\mathrm{N}$ & $\mathrm{N}$ \\
\hline LHX2_03 & $\mathrm{F}$ & 22 & $5 / 14 / 14$ & SS & Alive & & & & $\mathrm{Y}$ & $\mathrm{Y}$ \\
\hline LHX2_04 & $\mathrm{F}$ & 22 & $5 / 14 / 14$ & SS & Alive & & & & $\mathrm{Y}$ & $\mathrm{Y}$ \\
\hline LHX2_05 & $\mathrm{F}$ & 22 & $5 / 14 / 14$ & SS & Alive & & & & $\mathrm{Y}$ & $\mathrm{N}$ \\
\hline LHX2_09 & $\mathrm{F}$ & 14 & 8/28/14 & FW & Alive & & & & $\mathrm{Y}$ & $\mathrm{N}$ \\
\hline LHX2_10 & $\mathrm{F}$ & 26 & $8 / 28 / 14$ & FW & Alive & & & & $\mathrm{Y}$ & $\mathrm{Y}$ \\
\hline LHX2_12 & $\mathrm{F}$ & 26 & 8/28/14 & FW & Alive & & & & $\mathrm{Y}$ & $\mathrm{N}$ \\
\hline TJ22 & $\mathrm{F}$ & 17 & $11 / 22 / 05$ & SS, FW & Alive & & & & $\mathrm{Y}$ & $\mathrm{N}$ \\
\hline TJ23 & M & 17 & $11 / 22 / 05$ & FW & Alive & & & & $\mathrm{Y}$ & $\mathrm{N}$ \\
\hline TJ24 & M & 22 & 4/17/06 & SS & Alive & & & & $\mathrm{Y}$ & $\mathrm{N}$ \\
\hline TJ25 & M & 22 & $4 / 17 / 06$ & SS & Alive & & & & $\mathrm{Y}$ & $\mathrm{N}$ \\
\hline TJ26 & M & 22 & $4 / 17 / 06$ & SS & Alive & & & & $\mathrm{Y}$ & $\mathrm{N}$ \\
\hline TJ34 & M & 15 & $10 / 9 / 07$ & FW, SS & Alive & & & & $\mathrm{Y}$ & $\mathrm{Y}$ \\
\hline TJ36 & M & 15 & $10 / 9 / 07$ & FW & Alive & & & & $\mathrm{Y}$ & $\mathrm{Y}$ \\
\hline TJ38 & M & 22 & $4 / 29 / 08$ & SS & Alive & & & & $\mathrm{Y}$ & $\mathrm{Y}$ \\
\hline TJ39 & M & 22 & 4/29/08 & SS & Alive & & & & $\mathrm{Y}$ & $\mathrm{Y}$ \\
\hline TJ40 & $\mathrm{F}$ & 22 & $4 / 29 / 08$ & SS & Alive & & & & $\mathrm{Y}$ & $\mathrm{Y}$ \\
\hline TJ41 & M & 22 & 4/29/08 & SS & Alive & & & & $\mathrm{Y}$ & $\mathrm{Y}$ \\
\hline TJ45 & M & 16 & $11 / 12 / 08$ & FW & Alive & & & & $\mathrm{Y}$ & $\mathrm{Y}$ \\
\hline TJ48 & M & 16 & $11 / 11 / 08$ & SS, FW & Alive & & & & $\mathrm{Y}$ & $\mathrm{Y}$ \\
\hline TJ50 & $\mathrm{M}$ & 13 & $7 / 29 / 09$ & SS & Alive & & & & $\mathrm{N}$ & $\mathrm{Y}$ \\
\hline TJ53 & $\mathrm{M}$ & 14 & 9/10/09 & FW & Alive & & & & $\mathrm{N}$ & $\mathrm{N}$ \\
\hline TJ55 & $\mathrm{M}$ & 13 & 7/29/09 & FW, SS & Alive & & & & $\mathrm{Y}$ & $\mathrm{Y}$ \\
\hline TJ56 & $\mathrm{M}$ & 17 & $11 / 24 / 10$ & FW & Alive & & & & $\mathrm{Y}$ & $\mathrm{Y}$ \\
\hline TJ60 & $\mathrm{F}$ & 18 & $12 / 20 / 10$ & FW & Alive & & & & $\mathrm{Y}$ & $\mathrm{Y}$ \\
\hline TJ61 & M & 12 & $6 / 29 / 11$ & SS & Alive & & & & $\mathrm{N}$ & $\mathrm{Y}$ \\
\hline
\end{tabular}

\subsection{Diving behaviors}

Data transmissions received via Argos were decoded in the program DAP (Wildlife Computers). For some individuals $(\mathrm{n}=7$ ), the raw diving data could not be correctly decoded by DAP and data from these individuals were not used. Clean data were processed in $\mathrm{R}$ version 3.5.1 using R Studio. Diving data consisted of binned dive depth $(\mathrm{m})$, dive duration (min), and time at depth (TAD; \%). TAD is the percentage of time spent in any given depth bin (m) for each $6 \mathrm{~h}$ recording period. Data processing 
followed the methods of Thomton et al. (2008). Briefly, dive depths were recorded in the 14 following depth bins: 6-8, 9-16, 17-24, 25-32, 33-40, $41-50,51-60,61-70,71-80,81-100,101-120$, $121-160,161-200$, and $>201 \mathrm{~m}$. For SPLASH tags, dive duration was recorded in $30 \mathrm{~s}$ duration bins, with the 14th bin representing all dives $>390 \mathrm{~s}$. For SPOT-5 and SDR-T16 tags, dive duration was recorded in 1 min duration bins, with the 10th bin representing all dives $>9 \mathrm{~min}$. TAD for SPLASH tags was recorded in the following bins: 0-4, 9-16, 17-24, 25-32, 33-40, 41-50, 51-60, 61- 70, 71-80, and $>80 \mathrm{~m}$. For SPOT-5 and SDR-T16 tags, TAD was recorded in the following bins: 0-4, 9-16, 17-24, 25-32, 33-40, 41-48, 49-56, 57-62, 63-70, 71-78, $79-86$, and $>86 \mathrm{~m}$. Overall and daily means for dive depth $(\mathrm{m})$, dive duration $(\mathrm{min})$, and time wet $(\%)$ were calculated for all individuals (Table S1). As the 0-4 m depth bin in the TAD data represents an animal hauled out, time wet was calculated as the percent of time spent in all other bins combined. TAD data were not available for SPLASH tag animals $(\mathrm{n}=$ 6); therefore, they were removed from the analysis. Although average dive duration was calculated, it was not included in subsequent analysis due to collinearity with dive depth.

\subsection{Analysis: general horizontal and diving behaviors associated with predation events}

As previously described, between 2005 and 2014, 45 weaned SSL between the ages of 12 and 24 mo were released with LHX tags (Horning \& Mellish 2014, Horning et al. 2017). Through 2016, 20 mortalities had been detected (Horning \& Mellish 2014, Horning et al. 2017). Two of 20 returned insufficient data to determine causa mortis, and the remaining 18 were classified as predation events (Table 1) (Horning \& Mellish 2014, Horning et al. 2017). All animals that died, including the 2 inconclusive events, were initially considered for this analysis unless otherwise excluded (see next paragraph), as predation could not be ruled out as a cause of death.

Juvenile Steller sea lions exhibit seasonal differences in horizontal movement patterns (Bishop et al. 2018) and in diving behaviors (Fig. 1) (Mellish et al. 2007, Thomton et al. 2008). Therefore, in cases where SDR-derived behavioral data were collected in a season that did not match the season in which the mortality event occurred $(n=4$; Table 1$)$, the animal was removed from further analyses. Similarly, for animals that died, if there were behavioral data available for both seasons ( $\mathrm{n}=4$; Table 1 ), we only used the data from the season that temporally matched their mortality event. Including data limitations previously discussed during horizontal and diving data processing, this resulted in final data sets for 38 animals with horizontal data (22 alive, 16 dead) and 28 animals with diving data (16 alive, 12 dead; Table 1 ).

Two binomial generalized linear mixed-effects models (GLMMs) were run in $\mathrm{R}$ version 3.5.0 to assess the probability of mortality $(0=$ alive, $1=$ dead $)$ relative to (1) horizontal predictor variables and (2) vertical-diving predictor variables. For the horizontal behavior model, home range area $\left(\mathrm{km}^{2}\right)$, average distance traveled per trip $(\mathrm{m})$, sex, and interactions between season and home range area, and season and average trip distance were included as predictor variables to account for seasonal behavioral differences (Fig. 1). For the vertical-diving behavior model, average dive depth (m), percentage of time spent wet, sex, and interactions between season and average dive depth, and season and percentage of time wet were included as predictor variables. In both GLMMs, animal ID was included as a random effect to account for effects of individual heterogeneity introduced by pseudoreplication of live animals for which we included both seasons for which we had data $(n=42$ from $n=38$ IDs for the horizontal GLMM $; n=31$ from $n=28$ IDs for the vertical GLMM). Model selection was based on criteria established by Richards (2008). AICc values were calculated for the models described above, and for all simpler versions of both global models, including an intercept-only (null) model. The best models were identified as those with the lowest AICc. Additionally, we retained any models with a $\triangle \mathrm{AICc} \leq 6$, excluding those that were more complicated versions of models with lower AICc scores (Richards 2008). We used the R package DHARMa to conduct validation of the residuals for the best models (Fig. S1).

\subsection{Analysis: ante-mortem behaviors at a fine temporal scale}

Three animals in our study died with their SDR still attached and transmitting on the day of their confirmed predation event (TJ33, TJ47, and TJ58), whereas for most animals, the SDR stopped transmitting due to other reasons. The most common cause for end-of-record (EOR) is likely either exhaustion of the primary batteries powering the device, or the device falling off due to weakened attachment or being shed during the annual molt (Kooyman et al. 2015). Other possible causes may include technical device failures 

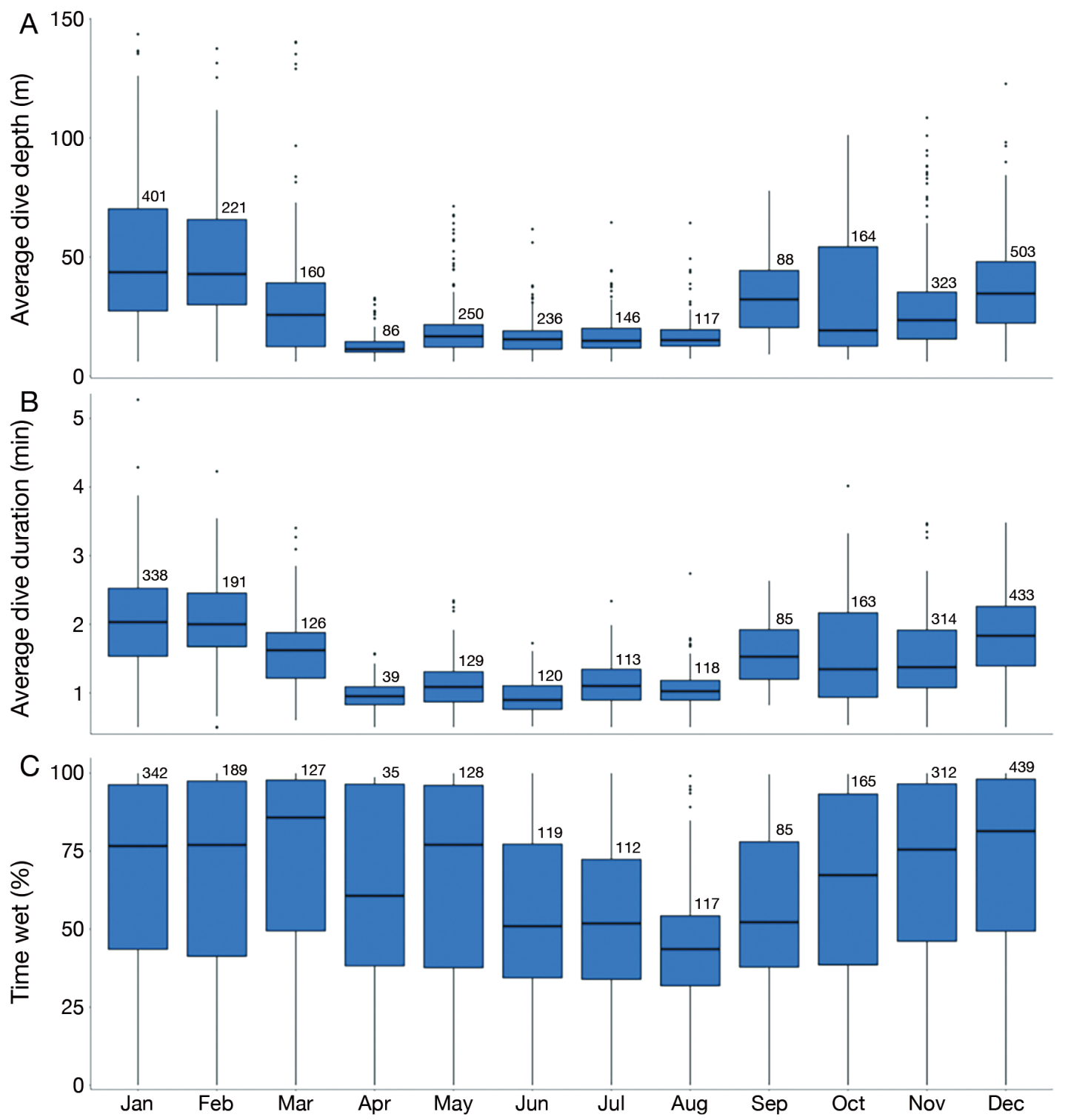

Fig. 1. Seasonal variations in diving behavior of juvenile Steller sea lions $(n=28)$ including individuals' $(A)$ average daily dive depth (m), (B) average daily dive duration (min), and (C) average percent time wet per day. Boxes represent the interquartile range around the median (dark line). Whiskers represent the 75 th and 25 th percentiles, and circles outside of whiskers represent possible outliers. Numbers above boxplots indicate the total number of samples in each month

(e.g. software lockup, antenna broken off) or mortality of the host animal. The 3 predation events concurrent with the end of the telemetry record provided an additional opportunity to investigate fine-scale differences in behavior associated with predation events. Specifically, we explored if the difference between behaviors at the end of a tracking data set and the average behavior of an individual varied based on whether the end of track represented a mortality. To do this, we first selected all animals that had greater than $50 \mathrm{~d}$ of dive data in the season in which their SDR record ended ( $n=16$ for dive depth; $n=11$ for percent time wet). For each animal, the mean dive depth and mean percent time wet were calculated across the last $3 \mathrm{~d}$ of tracking data. We then selected a day at random from the same season as when their track ended, and starting with that date, calculated the mean dive depth and percent time wet across a window of the next $3 \mathrm{~d}$ for each individual. The difference in mean dive depth $\left(D_{\text {depth }}\right)$ and mean percent time wet $\left(D_{\text {wet }}\right)$ between the last $3 \mathrm{~d}$ and the random window was then calculated for each animal. Negative values for $D$ indicated that an animal dove shallower or spent less time wet at the end of its track, and positive values indicated that an animal dove deeper or spent more time wet at the end of its track. We then performed a 
non-parametric Wilcoxon signed-rank test to compare $D_{\text {depth }}$ between animals with end of track mortality (n $=3$ ) and EOR ( $\mathrm{n}=13$ ), and to compare $D_{\text {wet }}$ between animals with end of track mortality $(n=3)$ and EOR ( $\mathrm{n}$ $=8$ ). Due to the small sample size of animals with mortality at the end of their tracking data, we repeated this process 50 times, and we considered the differences between groups significant if $>5 \%$ of the replicate trials resulted in a p-value $<0.05$.

\section{RESULTS}

\subsection{Horizontal and vertical behaviors associated with mortality}

Exploratory analysis revealed that there was considerable seasonal variation apparent in both dive depth and dive duration (Fig. 1). When looking at seasonal behavioral patterns as predictors of mortality, there was no evidence to support a relationship between individuals' horizontal movement patterns and vital status; the intercept-only null model was the best model (Table 2A). When considering vertical movement and haul-out patterns, percentage of time spent wet and an interaction between percentage of time wet and season were retained in the best model for predicting mortality; however, this model only accounted for $30 \%$ of overall model weight (Table 2B). Probability of mortality increased as the percentage of time wet decreased, but this pattern was only apparent in the summer (Fig. 2). The second-best model from our selection criteria, and the only other model with a $\triangle \mathrm{AICC}<6$ that was not a nested version of a simpler model, was the null model (Table 2B).

Table 2. Binomial generalized mixed-effects linear models predicting juvenile Steller sea lion vital status $($ alive $=0$, dead $=1)$ from seasonal (A) horizontal movement patterns and (B) vertical movement patterns. All models that met our selection criteria (Richards 2008) are shown above the dashed lines and include the coefficient estimate for any fixed effects retained in the model. Models that had a $\Delta \mathrm{AICc} \leq 6$ but were a more complicated version of a model that had a lower AICc score are shown with the variables included indicated by an ' $\mathrm{x}$ '

\begin{tabular}{|c|c|c|c|c|c|c|c|c|c|c|}
\hline (A) & $\begin{array}{c}\text { Horizontal } \\
\text { distance } \\
\text { model }\end{array}$ & $\begin{array}{c}\text { Trip } \\
\text { distance }\end{array}$ & $\begin{array}{l}\text { Home } \\
\text { range }\end{array}$ & $\begin{array}{c}\text { Trip } \\
\text { distance } \\
\times \text { season }\end{array}$ & $\begin{array}{c}\text { Home } \\
\text { range } \\
\times \text { season }\end{array}$ & Sex & df & $\mathrm{AICc}$ & $\Delta \mathrm{AIC}$ & Weight \\
\hline & 1 & & & & & & 2 & 59.8 & 0 & 0.300 \\
\hline & 2 & $\mathrm{x}$ & & & & & 3 & 61.5 & 1.66 & 0.131 \\
\hline & 3 & & $\mathrm{x}$ & & & & 3 & 61.8 & 1.99 & 0.111 \\
\hline & 4 & & & & & $\mathrm{x}$ & 3 & 61.9 & 2.06 & 0.107 \\
\hline & 5 & & $\mathrm{x}$ & & $\mathrm{x}$ & & 4 & 62.7 & 2.93 & 0.069 \\
\hline & 6 & $\mathrm{x}$ & & $\mathrm{x}$ & & & 4 & 63.0 & 3.24 & 0.059 \\
\hline & 7 & $\mathrm{x}$ & & & & $\mathrm{x}$ & 4 & 63.7 & 3.86 & 0.043 \\
\hline & 8 & $\mathrm{x}$ & $\mathrm{x}$ & & & & 4 & 63.9 & 4.11 & 0.038 \\
\hline & 9 & & $\mathrm{x}$ & & & $\mathrm{x}$ & 4 & 64.1 & 4.28 & 0.035 \\
\hline & 10 & & $\mathrm{x}$ & & $\mathrm{x}$ & $\mathrm{x}$ & 5 & 65.1 & 5.27 & 0.022 \\
\hline & 11 & $\mathrm{x}$ & $\mathrm{x}$ & & $\mathrm{x}$ & & 5 & 65.2 & 5.40 & 0.020 \\
\hline & 12 & $\hat{x}$ & & $\mathrm{x}$ & & $\mathrm{x}$ & 5 & 65.4 & 5.62 & 0.018 \\
\hline & 13 & $\mathrm{x}$ & $\mathrm{x}$ & $\mathrm{x}$ & & & 5 & 65.6 & 5.79 & 0.017 \\
\hline \multirow[t]{13}{*}{ (B) } & $\begin{array}{c}\text { Vertical } \\
\text { distance } \\
\text { model }\end{array}$ & $\begin{array}{c}\text { Dive } \\
\text { depth }\end{array}$ & $\begin{array}{l}\text { Time } \\
\text { wet }\end{array}$ & $\begin{array}{c}\text { Dive } \\
\text { depth } \\
\times \text { season }\end{array}$ & $\begin{array}{c}\text { Time } \\
\text { wet } \\
\times \text { season }\end{array}$ & Sex & df & $\mathrm{AICc}$ & $\Delta \mathrm{AIC}$ & Weight \\
\hline & 1 & & -0.096 & & 0.045 & & 4 & 44.1 & 0.00 & 0.309 \\
\hline & 2 & & & & & & 2 & 45.6 & 1.44 & 0.150 \\
\hline & 3 & $\mathrm{x}$ & $\mathrm{x}$ & & $\mathrm{x}$ & & 5 & 46.6 & 2.46 & 0.090 \\
\hline & 4 & $\mathrm{x}$ & & & & & 3 & 46.6 & 2.50 & 0.088 \\
\hline & 5 & & $\mathrm{x}$ & & $\mathrm{x}$ & $\mathrm{x}$ & 5 & 47.0 & 2.84 & 0.075 \\
\hline & 6 & & $\mathrm{x}$ & & & & 3 & 47.7 & 3.59 & 0.051 \\
\hline & 7 & & & & & $\mathrm{x}$ & 3 & 48.0 & 3.87 & 0.044 \\
\hline & 8 & $\mathrm{x}$ & $\mathrm{x}$ & $\mathrm{x}$ & $\mathrm{x}$ & & 6 & 48.1 & 3.98 & 0.042 \\
\hline & 9 & $\mathrm{x}$ & $\hat{x}$ & & & & 4 & 48.8 & 4.72 & 0.029 \\
\hline & 10 & $\mathrm{x}$ & & $\mathrm{x}$ & & & 4 & 48.9 & 4.78 & 0.028 \\
\hline & 11 & $\mathrm{x}$ & & & & $\mathrm{x}$ & 4 & 49.3 & 5.15 & 0.024 \\
\hline & 12 & $\mathrm{x}$ & $\mathrm{x}$ & & $\mathrm{x}$ & $\mathrm{x}$ & 6 & 49.7 & 5.56 & 0.019 \\
\hline
\end{tabular}




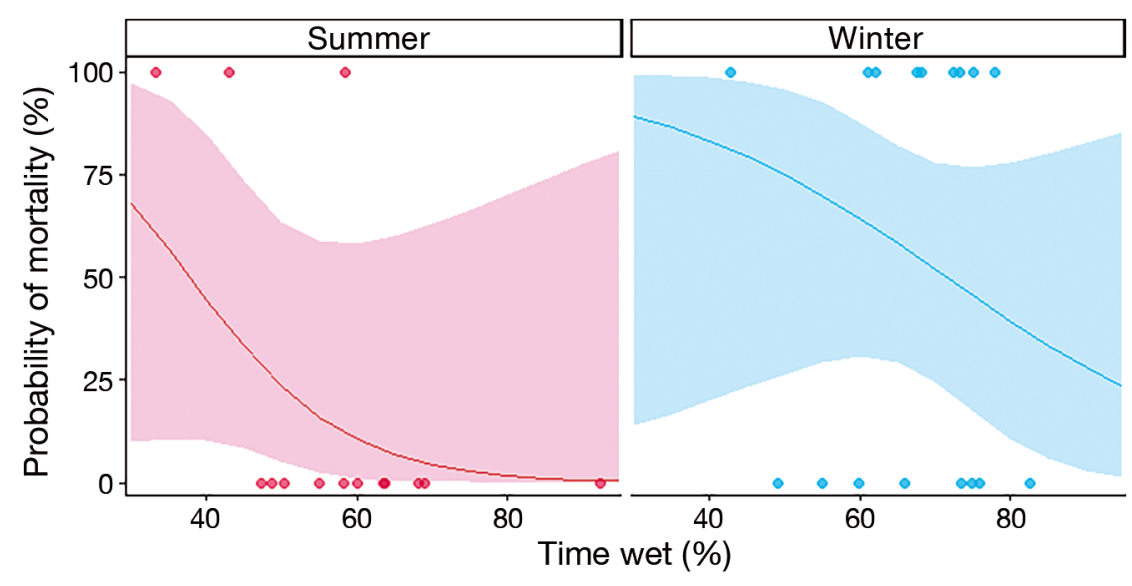

Fig. 2. Logistic regression from the best model for predicting the probability of mortality, relative to vertical behaviors for juvenile Steller sea lions. The percentage of time spent wet had a negative association with probability of mortality, with evidence of a stronger effect in spring-summer $(n=14)$ than in fallwinter $(n=17)$. Residual distributions are shown in Fig. S1 probability later in the juvenile's life, when seasonal effects were considered. Also, 3 juveniles appeared to conduct shallower dives in the days preceding their death by predation than during other periods at sea within the same season.

Overall, our results suggest that the likelihood of predation for the individuals in this study may be affected by variables that were not directly tested here, but that may be indirectly linked to our observed parameters. For example, we found some evidence suggesting individuals that spent less time wet, and more time hauled out, had a greater probability of mortality. Individuals that are more temporally and spatially associated with haul-outs may also spend more time in the water near haul-outs. Such a pattern, particularly in the summer, when our observed effect was stronger, might expose these individuals to greater predation risk by specialist predators known to target sea lion rookeries, such as transient killer whales Orcinus orca (Heise et al. 2003, Maniscalco et al. 2007). The finding of shallower diving by the 3 animals tracked until just before death is also consistent with observed evasion patterns exhibited by harbor seals Phoca vitulina when being actively pursued by killer whales (Womble et al. 2007).

Opportunistic and generalist predators, such as sharks, are also known to predate on Steller sea lions (Sigler et al. 2006, Frid et al. 2009). Data collected from some predation events associated with the present study specifically suggest Pacific sleeper sharks Somniosus pacificus as a likely predator in at least 5 mortalities (see Horning \& Mellish 2014). While our understanding of Pacific sleeper shark ecology is limited, one study found that Pacific sleeper sharks spent $75 \%$ of the time at depths greater than $50 \mathrm{~m}$ (Hulbert et al. 2006). Our data indicated that juvenile Steller sea lions in the same region, the Gulf of Alaska, typically only dive to depths $>50 \mathrm{~m}$ in the winter, thus predation by sharks would most likely occur at the upper limit of Pacific sleeper shark vertical movements, and more likely in winter than summer. While our results did not indicate that individuals' average dive depth was associated with probability of mortality, $65 \%$ of the mortalities in our study were observed in fall/winter.

While the resolution of our data in conjunction with small sample sizes poses challenges for the predicing had a weak, negative relationship with predation 
tive potential of our results at the population level, together, our findings support the hypothesis by Frid et al. (2009) that posits a combination of opportunist and specialist predators affecting Steller sea lions in the region. Disentangling the behavioral patterns and risk of predation in a multi-predator system is challenging (Willems \& Hill 2009), and it is at present unclear how the differential effects of multiple predator types may be reflected in assessments of individual sea lion behavior. We were unable to include predator type as an interactive term in our analysis as there are only 5 mortalities likely to be associated with sleeper shark predation, whereas the nature of the predator could not be determined in the remaining 13 mortalities clearly identified as predation events. Future work that includes information on the relative incidence of events attributable to one predator or another - the actual amount of predation pressure from killer whales and sharks seasonally would enable a better understanding of the drivers associated with consumptive effects of predation in this system. Identifying the predator species can be challenging in both terrestrial and marine environments, particularly if carcasses cannot be recovered for visual or molecular evaluation (Mumma et al. 2014). This can have implications for using predator control measures as a management tool (Ripple et al. 2019). The development of advanced signal processing algorithms to integrate information from multiple sensors (e.g. temperature, motion, depth), including novel sensors (e.g. ingestion), could improve the ability to identify predators, and represents an important area of future tag development.

Though not directly assessed in the present study, it is also important to consider how the behaviors we observed in our data might be influenced by risk, as perceived by juvenile sea lions (non-consumptive effects). An expanding body of literature suggests that interactions between resource availability and predators can influence foraging decisions and have associated fitness consequences (Heithaus et al. 2008, Frid et al. 2009). Behavioral patterns observed in juveniles, if responsive to perceived risk or possibly a risk-reward trade-off, might therefore change during late ontogeny as individual foraging strategies emerge. In our data set, the majority of mortality events occurred within $1.5 \mathrm{yr}$ of the behavioral data, an age where the animals were still considered juveniles when predation occurred. In a single case, the mortality event occurred approximately $3.5 \mathrm{yr}$ later. Like many pinnipeds, Steller sea lions exhibit physiological and behavioral ontogeny of diving patterns within their first year (Pitcher et al. 2005, Richmond et al. 2006, Rehberg \& Burns 2008). However, currently there is very little known about the development of individual behavioral strategies among Steller sea lions beyond this period, i.e. from juvenile to adult stages. Our data set was limited in assessing these differences due to both the relatively short duration of external tracking and the influence that seasonal behavioral changes have in masking individual patterns (Fig. 1). However, for other marine meso-predators, fidelity to an adult foraging strategy relatively earlier in life is associated with increased longevity across individuals (Authier et al. 2012). Thus, further investigations into how the long-term behavioral profiles of individuals relate to the tradeoffs between resource acquisition and the likelihood of predation could provide insights into the vulnerability of individuals within endangered populations.

Acknowledgements. We thank all researchers and teams that participated in the Transient Juvenile Steller sea lion project, specifically co-Principal Investigator, J. E. Mellish. This study was carried out in strict compliance with all applicable animal care and use guidelines under the US Animal Welfare Act and was approved as required under the US Marine Mammal Protection Act and the US Endangered Species Act by the National Marine Fisheries Service (permit numbers 1034-1685, 1034-1887, 881-1890, 881-1668, 14335, and 14336) and by the Institutional Animal Care and Use Committees of the Alaska Sea Life Center (protocol numbers 02-015, 03-007, 05-002, 06-001，08-005, and R1009-04). Data collection was supported by these awards: NOAA NA17FX1429, North Pacific Research Board (NPRB) R1011 and R1310, Pollock Conservation Cooperative Research Center G5498, the North Pacific Fisheries Foundation, and the Alaska Sea Life Center with the use of US Department of Commerce funds. Data analysis was supported by NPRB award R1512. The funders had no role in study design, data collection and analysis, decision to publish, or preparation of the manuscript.

\section{LITERATURE CITED}

Authier M, Bentaleb I, Ponchon A, Martin C, Guinet C (2012) Foraging fidelity as a recipe for a long life: foraging strategy and longevity in male southern elephant seals. PLOS ONE 7:e32026

Bishop A, Brown C, Rehberg M, Torres L, Horning M (2018) Juvenile Steller sea lion (Eumetopias jubatus) utilization distributions in the Gulf of Alaska. Mov Ecol 6:6

* Blumstein DT, Daniel JC, Bryant AA (2001) Anti-predator behavior of Vancouver Island marmots: using congeners to evaluate abilities of a critically endangered mammal. Ethology 107:1-14

*Breed GA, Matthews CJD, Marcoux M, Higdon JW and others (2017) Sustained disruption of narwhal habitat use and behavior in the presence of Arctic killer whales. Proc Natl Acad Sci USA 114:2628-2633

* Byström P, Persson L, Whalström E (1998) Competing predators and prey: juvenile bottlenecks in whole-lake experiments. Ecology 79:2153-2167 
Choh Y, Ignacio M, Maurice WS, Janssen A (2012) Predator-prey role reversals, juvenile experience and adult antipredator behaviour. Sci Rep 2:728

Ciuti S, Northrup JM, Muhly TB, Simi S, Musiani M, Pitt JA, Boyce MS (2012) Effects of humans on behaviour of wildlife exceed those of natural predators in a landscape of fear. PLOS ONE 7:e50611

Frid A, Baker GG, Dill LM (2006) Do resource declines increase predation rates on North Pacific harbor seals? A behavior-based plausibility model. Mar Ecol Prog Ser 312:265-275

Frid A, Heithaus MR, Dill LM (2007) Dangerous dive cycles and the proverbial ostrich. Oikos 116:893-902

Frid A, Burns J, Baker GG, Thorne RE (2009) Predicting synergistic effects of resources and predators on foraging decisions by juvenile Steller sea lions. Oecologia 158: 775-786

* Hamilton IM, Heithaus MR (2001) The effects of temporal variation in predation risk on anti-predator behaviour: and empirical test using marine snails. Proc Biol Sci 268: 2585-2588

* Hammerschlag N, Broderick AC, Coker JW, Coyne MS and others (2015) Evaluating the landscape of fear between apex predatory sharks and mobile sea turtles across a large dynamic seascape. Ecology 96:2117-2126

Hays GC, Ferreira LC, Sequeira AMM, Meekan MG and others (2016) Key questions in marine megafauna movement ecology. Trends Ecol Evol 31:463-475

Heise K, Barrett-Lennard LG, Saulitis E, Matkin C, Bain D (2003) Examining the evidence for killer whale predation on Steller sea lions in British Columbia and Alaska. Aquat Mamm 29:325-334

*Heithaus MR, Wirsing AJ, Thomson JA, Burkholder DA (2008) A review of lethal and non-lethal effects of predators on adult marine turtles. J Exp Mar Biol Ecol 356: $43-51$

* Holmes EE, York AE (2003) Using age structure to detect impacts on threatened populations: a case study with Steller sea lions. Conserv Biol 17:1794-1806

Horning M, Hill RD (2005) Designing an archival satellite transmitter for life-long deployments on oceanic vertebrates: the life history transmitter. IEEE J Oceanic Eng 30:807-817

Horning M, Mellish JAE (2009) Spatially explicit detection of predation on individual pinnipeds from implanted post-mortem satellite data transmitters. Endang Species Res 10:135-143

Horning M, Mellish JAE (2012) Predation on an upper trophic marine predator, the Steller sea lion: evaluating high juvenile mortality in a density dependent conceptual framework. PLOS ONE 7:e30173

Horning M, Mellish JAE (2014) In cold blood: evidence of Pacific sleeper shark (Somniosus pacificus) predation on Steller sea lions (Eumetopias jubatus) in the Gulf of Alaska. Fish Bull 112:297-310

* Horning M, Haulena M, Tuomi PA, Mellish JAE (2008) Intraperitoneal implantation of life-long telemetry transmitters in otariids. BMC Vet Res 4:51

Horning M, Haulena M, Tuomi PA, Mellish JE and others (2017) Best practice recommendations for the use of fully implanted telemetry devices in pinnipeds. Anim Biotelem 5:13

Hulbert LB, Sigler MF, Lunsford CR (2006) Depth and movement behaviour of the Pacific sleeper shark in the northeast Pacific Ocean. J Fish Biol 69:406-425
Iribarren C, Kotler BP (2012) Foraging patterns of habitat use reveal landscape of fear of Nubian ibex Capra nubiana. Wildl Biol 18:194-201

Jones KA, Godin JJ (2010) Are fast explorers slow reactors? Linking personality type and anti-predator behaviour. Proc R Soc B 277:625-632

Kauffman MJ, Brodie JF, Jules ES (2010) Are wolves saving Yellowstone's aspen? A landscape-level test of a behaviorally mediated trophic cascade. Ecology 91:2742-2755

*King JC, Gelatt TS, Pitcher KW, Pendleton GW (2007) A field-based method for estimating age in free-ranging Steller sea lions (Eumetopias jubatus) less than twentyfour months of age. Mar Mamm Sci 23:262-271

Kohl MT, Stahler DR, Metz MC, Forester JD and others (2018) Diel predator activity drives a dynamic landscape of fear. Ecol Monogr 88:638-652

* Kooyman GL, McDonald BI, Goetz KT (2015) Why do satellite transmitters on emperor penguins stop transmitting? Anim Biotelem 3:54

Krams I, Kivleniece I, Kuusik A, Krama T and others (2013) Predation selects for low resting metabolic rate and consistent individual differences in anti-predator behavior in a beetle. Acta Ethol 16:163-172

*Laundré JW, Hernández L, Aletndorf KB (2001) Wolves, elk, and bison: reestablishing the 'landscape of fear' in Yellowstone National Park, USA Can J Zool 79:1401-1409

* Lima SL, Dill LM (1990) Behavioural decisions made under the risk of predation: a review and prospectus. Can J Zool 68:619-640

* Lone K, Loe LE, Gobbakken T, Linnell JDC, Odden J, Remmen J, Mysterud A (2014) Living and dying in a multipredator landscape of fear: roe deer are squeezed by contrasting pattern of predation risk imposed by lynx and humans. Oikos 123:641-651

* Lundvall D, Svanbäck R, Persson L, Byström P (1999) Sizedependent predation in piscivores: interactions between predator foraging and prey avoidance abilities. Can J Fish Aquat Sci 56:1285-1292

*Maniscalco JM, Matkin CO, Maldini D, Calkins DG, Atkinson S (2007) Assessing killer whale predation on Steller sea lions from field observations in Kenai Fjords, Alaska. Mar Mamm Sci 23:306-321

* Mellish JE, Calkins DG, Christen DR, Horning M, Rea LD, Atkinson SK (2006) Temporary captivity as a research tool: comprehensive study of wild pinnipeds under controlled conditions. Aquat Mamm 32:58

* Mellish JA, Thomton J, Horning M (2007) Physiological and behavioral response to intra-abdominal transmitter implantation in Steller sea lions. J Exp Mar Biol Ecol 351: 283-293

Kumma MA, Soulliere CE, Mahoney SP, Waits LP (2014) Enhanced understanding of predator-prey relationships using molecular methods to identify predator species, individual and sex. Mol Ecol Resour 14:100-108

NMFS (National Marine Fisheries Service) (2010) ESA Section 7 Biological Opinion on the Alaska Groundfish Fisheries NMFS, Juneau, AK, p 472. https://alaskafisheries. noaa.gov/sites/default/files/biop1210_all.pdf

* Pascual MA, Adkison MD (1994) The decline of the Steller sea lion in the Northeast Pacific: demography, harvest or environment? Ecol Appl 4:393-403

* Pitcher KW, Rehberg MJ, Pendleton GW, Raum-Suryan KL, Gelatt TS, Swain UG, Sigler MF (2005) Ontogeny of dive performance in pup and juvenile Steller sea lions in Alaska. Can J Zool 83:1214-1231 
Raum-Suryan KL, Rehberg MJ, Pendleton GW, Pitcher KW, Gelatt TS (2004) Development of dispersal, movement patterns, and haul-out use by pup and juvenile Steller sea lions (Eumetopias jubatus) in Alaska. Mar Mamm Sci 20:823-850

Réale D, Festa-Bianchet M (2003) Predator-induced natural selection on temperament in bighorn ewes. Anim Behav 65:463-470

Richards SA (2008) Dealing with overdispersed count data in applied ecology. J Appl Ecol 45:218-227

Ripple WJ, Estes JA, Schmitz OJ, Constant V and others (2016) What is a trophic cascade? Trends Ecol Evol 31: 842-849

Ripple WJ, Miller SD, Schoen JW, Rabinowitch SP (2019) Large carnivores under assault in Alaska. PLOS Biol 17: e3000090

Seaman DE, Millspaugh JJ, Kernohan BJ, Brundige GC, Raedeke KJ, Gitzen RA (1999) Effects of sample size on kernel home range estimates. J Wildl Manag 63:739-747

Shuert C, Horning M, Mellish JA (2015) The effect of novel research activities on long-term survival of temporarily captive Steller sea lions (Eumetopias jubatus). PLOS ONE 10:e0141948

Sigler MF, Hulbert LB, Lunsford CR, Thompson NH, Burek K, O'Corry-Crowe G, Hirons AC (2006) Diet of Pacific sleeper shark, a potential Steller sea lion predator, in the north-east Pacific Ocean. J Fish Biol 69:392-405

Editorial responsibility: Clive McMahon,

Hobart, Tasmania, Australia
Thomton JD, Mellish JAE, Hennen DR, Horning M (2008) Juvenile Steller sea lion dive behavior following temporary captivity. Endang Species Res 4:195-205

* Tolon V, Dray S, Loison A, Zeileis A, Fischer C, Baubet E (2009) Responding to spatial and temporal variations in predation risk: space use of a game species in a changing landscape of fear. Can J Zool 87:1129-1137

Walsh MR, Reznick DN (2009) Phenotypic diversification across an environmental gradient: a role for predators and resource availability on the evolution of life histories. Evolution 63:3201-3213

Williams TM, Estes JA, Doak DF, Springer AM (2004) Killer appetites: assessing the role of predators in ecological communities. Ecology 85:3373-3384

Willems EP, Hill RA (2009) Predator-specific landscapes of fear and resource distribution: effects on spatial range use. Ecology 90:546-555

Wirsing AJ, Heithaus MR, Frid A, Dill LM (2008) Seascapes of fear: evaluating sublethal effects experienced and generated by marine mammals. Mar Mamm Sci $24: 1-15$

*Womble JN, Gende SM, Blundell GM (2007) Dive behavior of a harbor seal (Phoca vitulina richardii) in the presence of transient killer whales (Orcinus orca) in Glacier Bay National Park, Alaska. Mar Mamm Sci 23:203-208

* York AE (1994) The population dynamics of northern sea lions, 1975 1985. Mar Mamm Sci 10:38-51

Submitted: April 11, 2019; Accepted: October 17, 2019

Proofs received from author(s): December 14, 2019 